\title{
Dance in the system of contemporary integrative Art Studies
}

\author{
Tatiana Portnova ${ }^{1, *}$ \\ ${ }^{1}$ Russian State University named after A. N. Kosygin, 117997, 33-1 Sadovnicheskaya str., Moscow, \\ Russia
}

\begin{abstract}
The paper considers innovative models of interaction between art courses in the format of their comprehensive study on the basis of the new author's program "Ballet and synthesis of plastic arts," created for the direction "Choreographic Art" of various profiles (direction of Ballet Theater, Pedagogy of Choreography, Performing Arts). The conceptual approaches outlined in the program, based on interdisciplinary contacts of related arts, make it possible to include it in the professional cycle of Master's programs and additional training at universities and other organizations that carry out educational activities, as well as in the system of retraining directors of theaters in the transition to modern design technologies.
\end{abstract}

\section{Introduction}

The program is formed on the basis of author's scientific, educational, methodological, and project development of an interdisciplinary nature. Spiritual demands of contemporary society require a high level of understanding of reality, which is correlated with the general objectives of the culture of the 21 st century. Interaction and interpenetration of sciences became an indispensable condition for their further development. As of today, it is difficult to find a major problem of one science, which would not attract the attention of a whole complex of others. The tendency to their synthesis is unquestionable. We observe this in the emergence and development of new types of artistic creativity, which is caused by an urgent need for life to create a single and integral scientific and cultural picture of the world that corresponds to the current level of the accumulated knowledge. This requires improving professional skills of the managers, screenwriters of operators, artists, actors, art theorists, awakening the spirit of innovative ideas. There should be a bold search for new topics and expressive possibilities of the language of the ballet theater. These tasks arise not only for Ballet Studies in the narrow sense, but also for the Pedagogy of Art and synthetic Art History, should be reflected in the curriculum of the Master's level, being oriented to a systematic study not only of history but also of contemporary theoretical and practical problems of the Theatrical Arts.

A considerable number of articles and books have been devoted to the forms of fine Arts; many art critics and artists were engaged in substantiating its "grammar" from various

\footnotetext{
* Corresponding author: infotatiana-p@ mail.ru
} 
conceptual positions $[3,4]$. However, there are absolutely no scholarly works exploring the plastic language of graphics, painting, sculpture, and their points of contact with choreography (despite the fact that the plastic form is one of the main sources, and somewhere the main source, of information). In the plastic form, both the silhouette pattern of volumes and the constructive-spatial structure are vested; they receive their plastic expression of the nuances of rhythm and harmony of the relations; and even complex artistic associations are born under the influence of the plastic principle. We can talk about the impact of the sculptural and plastic images of Michelangelo and the uniqueness of dance plastics in the choreography of $\mathrm{K}$. Goleizovsky, the plastic expressiveness of V. Serov's graphic drawings and the graphics of M. Bejart's postures and movements, and finally the plasticity of K. Pissarro's painting and the color movement in performances of M. Fokine. But by what means is expressiveness of artistic plasticity achieved? Consider the specific features of the arts, especially stopping at the painting, highlighting the features of its artistic language, and try to find similarities with the plastic language of dance.

Goethe, speaking of the specific nature of Art, nevertheless pointed to the mobility of the boundaries between them: "The sculptor can be knocked out of the way by the painter, the painter is a mimist, and all the three can so confuse each other that none of them will stand on legs" [1]. The artist K. Yuon, considering painting, also wrote about enriching it with other forms of creativity [5]

The aforementioned authors persistently point to the synthetically working consciousness of the artist. In our conversation about the specific features of the Arts, we will simultaneously consider the expressive means of the Art of Choreography, finding analogies, parallels, and connections between them. It seems that such a synchronous approach has its advantages, because it helps to reveal more deeply the internal interrelationships between the separate linguistic structures of various arts, individual phenomena of artistic creativity. The Ballet Theater is a special kind of synthetic art. Synthetism of the theatrical form is the main point in the study of this art.

\section{Research design}

The existing practice marked the beginning of studying traditional theatrical disciplines in theatrical and creative educational institutions: "The History of Ballet," "The Art of the Choreographer," "The Choreographic Work," "The Choreographic Direction," "The Composition of Classical Dance," etc. However, an invaluable role in the learning process is to play courses based on innovative technologies for designing complex systems, using visual materials and other visual sources, attracting computer technologies and programs. In the new cultural context, there is the problem of enriching the choreographic language and the gradual replacement of the repertory theater and its traditional essence with a high-tech theater of stage design. Modern theatrical criticism in the evaluation of scenic works increasingly relies on a number of fundamental and applied disciplines: Art Criticism, Literary Criticism, Cultural Studies, Philosophy, Structuralistics, Linguistics, Source Study, going up to theatrical design, computer technologies, and polychological tools [6]. In different countries of the world, there are various educational programs being developed, including various Master's programs in the field of dance, movement therapy, and counseling $[7,8,13]$.

Some of them are based on the premise that dance is a special form of art, which calls for the integration of body, mind, and spirit [9, 10, 11]. The main goal of the Master's program proposed by us is the preparation of specialists of a creative profile for professional scientific, educational, project, intellectual-capacious activities by studying the field of scientific research, mastering the skills of interdisciplinary research and projects, mastering innovative intellectual technologies of generation, processing, representation of 
knowledge. The main tasks are to deepen, expand, and improve the basic professional knowledge and skills of listeners, to form the skills of a systematic approach, motivational guidelines for self-management of scientific and research activities, improvement and development of its own general intellectual, general cultural and scientific potential, as well as its application in the subject field of professional activity. The target audience is the graduates of the Bachelor's Degree in Choreography, Art Critics, and other related creative areas, applicants and participants in scientific and creative projects.

The scientific field and vectors of the study of the program "Ballet and the Synthesis of Plastic Arts" presupposes a broad study of the current topics related to the morphology of the ballet as a synthetic art form, various aspects of the interaction of stage dance and plastic arts (graphics, painting, sculpture, arts and crafts, architecture, and other forms of creativity) to the study of a qualitatively new artistic phenomenon, not reducible only to the sum of the integral components [12]. The laws of visual perception of scenography cause three compositional levels of the stage work, the relationship between the masses of the stage space, the light and shadow state of the performance, the plastic elaboration (depth) of the stage space. All this is reflected in the concept so important for the theory of scenography - the organization of a common theater space. It includes the following features: the architectural division of the theater into scenic and visual parts (topographic division), the interaction of the actor and the audience, being manifested in the context of the spatial environment; dynamics of mass development, consisting in the ratio of the linearity of their voltage; and finally a dialogue: the actor is the spectator in their spatial certainty. The concept of "organization of scenic space" includes the interdependence of the real (physically given) and surreal (artistically-sensed) scenic space in the theatrical performance. The real stage space, determined by the nature of the architectural interconnectedness of the stage and the auditorium, the type and characteristics of the stage, its technical equipment, scale of dimensions, - all of them change physically. The real scenic space changes due to the different interrelationships of its constituent masses, light state, color relationships, graphics. Remaining physically unchanged, it can change in artistic perception, depending on what is depicted on the stage and how it is filled with details.

The arrangement of the masses in the ensemble implies the relationship of the actors' ensemble on the stage and the ratio of the groups in the ensemble itself. Performers in the course of the theatrical performance form separate semantic groups that enter into complex spatial relations. At the same time, the size of groups, the construction line, the background on which they operate is identified or obscured. These dynamics of the masses is largely laid down in the dramatic material and is an important goal in the development of the stage image.

Thus, the organization of the stage space and the arrangement of the masses in the ensemble ensemble are the links of a single system that forms the first compositional level of the theory of scenography, which determines the interrelation of the masses of the scenic space.

The second compositional level of scenography that can be considered is the light-color state of a play based on the laws of light distribution. With the general solution of color in a picturesque picture, as well as in a ballet performance, light is connected. These concepts are inseparable. Light gives a new sound to the color; it largely shapes the mood, determines the nature of our perception. The problem of light in painting interested many artists, and they solved it in different ways. The brightest or, conversely, the darkest spot in the picture involuntarily attracts the attention of the viewer, which always takes into account both the painter and the choreographer in the realization of his idea. In the "Dying Swan" by M. Fokine, the cold blue stream of light closely follows the ballerina dressed in a 
swan pack, the dance of which is contrastingly drawn on a deep neutral background, giving rise to a dramatically sad theme.

Color in painting can have a symbolic meaning. We are used to the fact that colors are an aesthetic equivalent to reality, but they can, at the same time, be interpreted as a symbol, hinting at what sometimes cannot be said: whether it is the image of a god, of higher cosmic forces or otherworldly being. The deep symbolic essence of color can be revealed in the images of the ballet performance. Light in a ballet performance, in its external form, primarily works as a general illumination, a light saturation of the stage space. External light (the light of lighting devices) is designed to reveal the volume of the scene, its spatial certainty. This is only one facet of the light-color state of the play. The second is connected with the color definiteness of the space of the stage, which manifests itself in the color variety of scenic volumes, the objective world of the scene, in the color scale of the picturesque veils, in the color of the costumes, makeup, etc. All this can be called the inner light of scenic forms. The external light and closed light, that is, the color in the ballet work, find their completion in light-color interaction, as a result of which a light-color gamut of the whole spectacle, visual accents get into a dialogue with the plot-dramatic development line and the musical structure of the theatrical works. The third, the final compositional level of scenography can be the plastic depth of the stage space. As the actor acts on the scenic platform (the rhythm of body movements in space, facial expressions, gestures, postures, mise-en-scene construction), then the entire environment should become subordinate to him/her. At the same time, the stage environment (space) is in a dialogical relation with the mise-en-scene of the dance, and this dialogue can be built not only on the harmony, but also on the contradiction, which ultimately works to uncover the content of the ballet work. The composition of the in-depth spatiality of the forms of the play is manifested both in the plastic of the performers, in the plastic of the stage forms, and in their interrelationship in the process of creating plastic completeness.

The theatrical artist makes sketches, mock-ups of the artistic design of the future performance. Only after that, the theater's workshops begin to work on the design of the ballet. The theatrical artist works in close proximity with the director-choreographer, the author of the choreographic text. Sometimes, he/she significantly influences the picturesque-coloristic vision of the material on the image of dance [2]. In the process of joint work, the artist always sees work in dynamics, in motion. The dynamism of the dance action confronts the stage designer with specific problems of the coloristic solution of each episode, pictures, and actions.

The sketch of scenery is an image of the real environment of action, created on the basis of the libretto, the general artistic design, the ballet master's interpretation and the artist's emotional vision. In the ballets created by the choreographer Yu. Grigorovich and the artist S. Virsaladze, the choreographic idea always agrees, develops, and is strengthened by the thought of the artist. The costumes of Virsaladze's ballet characters are usually created based on a specific drawing of the dance, on the dynamic development of the character's image in the play. The color of a costume is always a moving spot of the soloist's dance, a moving color scale in the ensemble's dance. You can create a beautiful costume, but it would not "play" on stage, unless being "supported" by the background on which the artist moves. Therefore, in costume design, the interrelation between costume and decoration, costumes and the actor's ensemble should be artistically resolved. The costume must fit into the plastic of the movement, into the intonation of the stage work. Such a development of scenographic material, of course, assumes the true co-creation of the artist with the author-choreographer. Therefore, in the ballet performance, not only the picturesque image of the scenery, costumes with the architecture of the scene are important, but also the interconnectedness of choreographic images with the whole fabric of the performance is extremely relevant [12]. 


\section{Results and discussion}

The scope of master's studies can include little developed modern problems of the theory and history of the Ballet Theater, relating to classical choreography in the context of the organization of the stage space and the spatial arts interacting with it. These are the ideas of direction and movement in space, the questions of architectonics and the plastic form of the ballet performance, the criteria for portrayal in dance, the principles of interaction of expressive and visual means, the problems of retrospective and innovative stylistic trends in ballet, the methods of reconstructing the choreographic heritage, the questions of the addition of academic schools of classical dance and the overcoming their boundaries from tradition to the pioneering quest for a dance in an open environment, museum and other spaces.

Another aspect of scientific master's searches may be topics related to the composition of museum and private collections, mainly theatrical profile, storing the graphic materials of ballet iconography, and decoration.

Thus, all the platforms of the ballet theater with a complex of research problems that are in anyway in touch with the existing structure of the visual art image in the work of artists and choreographers are involved, as well as forecasting future new forms of visual visualization in the process of creating choreographic works.

The dominant author's discipline being included in the basic part of the preparation of masters in the direction "Choreographic Art" is the "Methodology of Scientific Research in Choreography." It aims to give students knowledge on the content and basic methods of research work, as well as to develop the initial skills of planning, organizing, and registering various kinds of research work. Formation of interest in research activities and the need for its implementation is another major focus of the research.

The methodological preparation of the future specialist in the field of scientific and pedagogical, choreography, staging, and research activities presupposes the formation of a methodological culture of undergraduates in the field of choreographic research, the formation of students' ideas about the methodology and methods of scientific research, and mastering the culture in the field of choice and literate the application of methods in the field of Choreographic Art.

Parallel courses that complement this discipline, creating a thematic specialized unit, are: "Modern Problems of Science and Art," "Analysis of Choreographic Works," "Synthesis of Spatial and Plastic Arts," "Costume and Scenic Decoration of Dance," "Scenography of Ballet Performance," "Philosophy of Dance," "Author's Concept, Form, Genre, and Vocabulary of a Choreographic Work," and "Art Criticism, Historical, Cultural, Psychological, and Pedagogical Approaches in Research and Critical Analysis of Works in Choreographic Art." The discipline "The Methodology of Scientific Research in Choreography" is fundamental for the study of all subsequent courses, since the knowledge and skills formed within its framework are methodological in nature and allow applying them in the field of modern technologies and methods of creating original creative projects and solving professional problems.

The method of mastering the Master's program includes lecturing, conducting practical classes, and interactive forms of research work (presentations, trainings, excursions, internships) during the first year of training. The lectures are provided on topics of theoretical importance. Practical studies are devoted to problematic issues and are called upon to form the analysis skills of the synthetic work of ballet art, drawing up programs for its structural study. Practical classes are designed to create skills to use knowledge about the features and specifics of various forms and genres of art, as well as the skills of directing a theatrical performance in the future professional and cultural activities. 
The course provides for the development of several scientific publications, educational and methodological developments, computer presentation projects, writing reviews for a ballet performance, organizing and conducting own integrative mini-study of the historical development in the Ballet Theater in one of the countries proposed, the analysis of a choreographic work of a certain genre; it is also possible to direct the visual decision of own performance in the context of a dialogue of spatial and plastic and art. The knowledge gained in the process of studying the program can be used in the passage of research practice.

\section{Conclusion}

The competences of the Master's program are aimed at the ability of graduates to introduce innovative technologies that take into account the needs of society, to design activities in the field of Culture and Art (projects of museums of theaters, art exhibitions and ballet exhibitions, houses of culture and creativity), to the protection and reconstruction of cultural values. They are also oriented towards the readiness to develop the goals and priorities of the scientific and creative activity of scientific research, educational institutions, and cultural institutions that realize the pedagogical, directorial, artistic-staging and actor-performing types of professional work of the choreographer and artist.

So, the ultimate goal of the integrated study of dance and plastic arts in the system of studying programs of integrative art history should be not only to highlight the individual aspects, links and components of this complex process, but also their organic and functional connection into a single integrated system. The modern teaching and scientific level should provide the necessary module, which increases the coefficient of spiritual, creative, and scientific comfort of the creative University.

The final importance of the Master's program consists in mastering the skills of collecting and processing information, the methodology for conducting scientific research in the field of Ballet and related Plastic Arts, with the basic rules for the use of professional vocabulary; conceptual - categorial apparatus of the art of integrative science, professional culture of the presentation of the material, and the skills of using sources and scientific literature in the process of creating a scientific text of the Master's thesis. Thus, the obtained scientific results would allow increasing the effectiveness of intellectual activity in the fields of Science, Culture and Art, Education, and Design.

\section{References}

1. I. Goethe, Articles and thoughts on art (Leningrad, Moscow, 1936)

2. E. Kiseleva, World of Science, Culture, Education, 6, 37, 2012)

3. Yu. Kondratenko, The language of scenic dance: species specificity and morphology (Saransk, 2009)

4. N. Terenteva, Chelyabinsk Humanitarians, 14, 1 (2011)

5. K. Yuon, About painting (Moscow, 1931)

6. T. Brown, Choreography as Visual Art: Middletown (Wesleyan University Press, Connecticut, 2016)

7. D. Carthy, Speaking about the unspeakable: non-verbal methods and experiences (2008)

8. S. Chaiklin, H. Wengrower, Movement therapy: life is dance (Routledge, Taylor \& Francis Group, New York, 2016) 
9. D. Davida, Fields in motion: ethnography in the worlds of dance (Wilfrid Laurier Univ. Press, 2011)

10. B. Klein and Gabriele, Dance and theory (2014)

11. B. Klein and Gabriele (Eds.), HAU Journal of Ethnographic Theory, 4, 2 (2014)

12. S. Lysenko, Journal of Siberian Federal University. Humanities \& Social Sciences, 6 (2016)

13. M. Lessons, Margaret H'Doubler and the beginning of dance in American education (Univ of Wisconsin Press, Madison, 2000) 